\title{
INTEGRATED MULTIMOTOR ELECTRICAL DC DRIVE FOR METALLURGICAL ROLLING TABLE
}

\author{
Marek Gała*, Kazimierz JAGIELA*, Andrzej JĄDERKO*, Janusz RAK* \\ ${ }^{*}$ Faculty of Electrical Engineering, Czestochowa University of Technology, Al. Armii Krajowej 17, 42-200 Częstochowa, Poland \\ "*Faculty of Management, Czestochowa University of Technology, Al. Armii Krajowej 17, $42-200$ Częstochowa, Poland \\ mgala@el.pcz.czest.pl, kazimierz.jagiela@gmail.com, aj@el.pcz.czest.pl, irak@el.pcz.czest.pl \\ received 7 September 2014, revised 25 May 2015, accepted 28 May 2015
}

\begin{abstract}
A drive system of a section of a metallurgical rolling table consisting of six dc motors, 2220 amperes of total current, fed from a single $A B B$ reversible thyristor converter has been described in this paper. Autonomous excitation circuits of the motors are fed from independent thyristor converters working in the so called MULTIFEX system linked with a supervisory high power converter. There are presented schemes of the DSL communication realized by FEX excitation cards of the motors using the SDSC card of the DCS-800-S02 converter and logic control system based on a PLC controller. The parameterization of the DCS-800 converter and the DCF 803 excitation systems was conducted using the DriveWindow software tool. Significant waveforms of voltages, currents and the estimated motor velocity are described and presented for the idle run as well as during transporting sheets discharged from a pusher furnace.
\end{abstract}

Key words: DC Drive System, Rolling Table, FEX Excitation System, Drivewindow Software

\section{INTRODUCTION}

Contemporary applications of complex drive systems are usually based on asynchronous squirrel-cage motors. Nevertheless, for technical and/or economical reasons, existing drives with DC motors are modernized by implementing highly specialized thyristor bridges with various control algorithms. Solutions presented in the literature include control systems based on the phase-locked loop synchronization (Abu-Rub et al., 2004; 2005) or on the mechanical vector reconstruction using a state variable observer (Guziński et al., 2009). In the Polish metallurgical and paper-making industry it is very common that after modernization the DC motors installed before remain in use adapted for powering from modern converters employing advanced control techniques, such as MASTER-FOLLOWER (Gała et al., 2009; Jagieła and Gała, 2008) or MULTIFEX (Multifex motor control for roller tables, 2008). Such solutions apply in principle to drives with electric motors of relatively high power. The reason is minimization of the drive modernization cost including installation of the power electronics supply system. Alternative replacement of a DC drive by an asynchronous drive with a frequency converter often entails mechanical and building modifications.

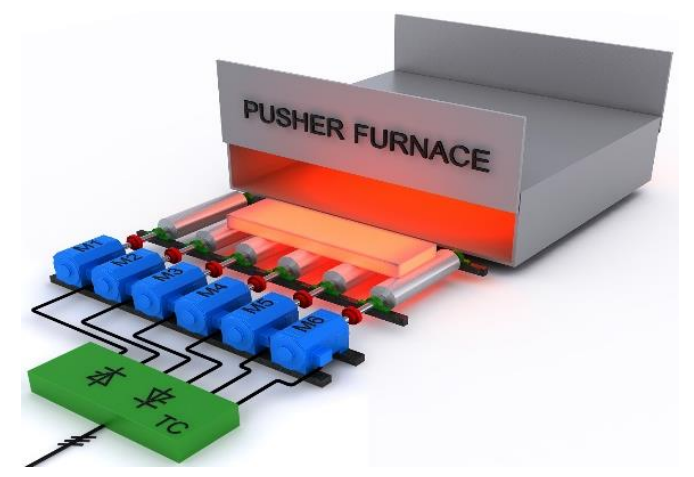

Fig. 1. Discharge rolling table with a separate drive of each roll
The subject of modernization described in this paper is discharge rolling table drive of a pusher furnace. There are many types and designs of components of such an electro-mechanical system, i.e. rolls, the mechanism of the torque transmission, a single motor or group of motors and a power electronics supply system. The two types of drives most often used in discharge rolling table systems are:

- multi-output reduction gear asynchronous drives with controlled angular velocity (Jagieła, 2003);

- separate drives of each roll with DC or AC motors.

A discharge rolling table with separate DC drives for the individual rolls is shown in Fig. 1.

The paper deals with an application of the ABB reversible thyristor converter type DCS800 S02, which feeds several to teens armature circuits of separately excited DC motors from a single DC circuit. The considered system is an original solution of the $A B B$ (Multifex motor control for roller tables, 2008) dedicated for rolling table drives. The control of the multimotor MULTIFEX system is based on a PLC controller. The drive is a part of a complex automation system of heating and conveyance of slabs on a plate rolling line.

A similar system, but with different control scheme, has been described in Kolar and Friedli (2013), where a model of a four-motor DC unit that drives two drums of a papermaking machine has been presented.

\section{MECHANICAL SYSTEM OF THE DISCHARGE ROLLING TABLE SECTION DRIVE}

The drive of the discharge rolling table section is a group drive system fed from a single converter TC (Fig. 1). Electric motors $\mathrm{M} 1 \div \mathrm{M} 6$ are coupled by connecting links directly to the rolls conveying slabs or a metal strip (Fig. 2). The direct coupling of the motors to the rolls results from using high-power and slow-speed motors that ensure enough torque to cope with the static load as well 
as with the impulse load due to eccentric impacts of the conveyed strip against the table rolls. The characteristics of the roll load torque versus time can be described by equation (1):

$$
\begin{aligned}
T_{L_{i}}(t)=T^{\varphi}(t) & -T^{\varphi}(t-\Delta \tau)+T_{S}(t-\Delta \tau) \\
& -T_{S}\left(t-t_{1_{i}}\right)
\end{aligned}
$$

where: $\Delta \tau=\frac{30 \cdot \varphi[\mathrm{rad}]}{2 \pi n}=\frac{\varphi[\circ]}{6 n}$ s; $n \in\left\langle n_{\min }, n_{\max }\right\rangle \mathrm{rpm}$, $t_{1 i}=\frac{v_{1}}{l_{r}+0.5 D_{z}} \cdot i, D_{z}-$ external diameter of the roll, $l_{r}-$ distance between the rolls, $v_{1}$ - slab/strip speed, $i$ - roll number.

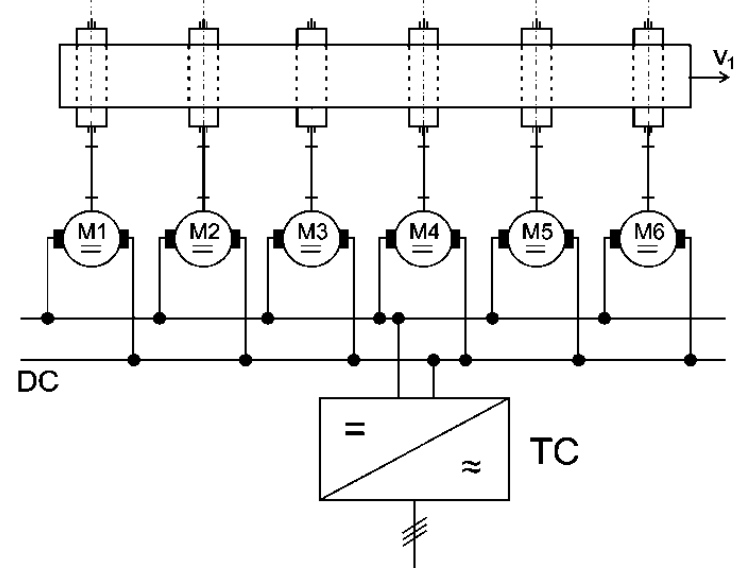

Fig. 2. Electromechanical system of the discharge rolling table drive

The static torque $T_{S}$ from the mass of the conveyed slabs can be determined using formula (2):

$T_{S}=\left[\left(m_{c}^{*}+m_{b}\right) \cdot f_{t} \cdot \frac{D_{t}}{2}+m_{c} \cdot f_{r} \cdot \frac{D_{z}}{2}\right] \cdot g$

where: $m_{c}^{*}=\frac{m_{c}}{N}$ mass of a conveyed slab per single roll, $\mathrm{mb}-$ mass of the roll drum, $N$ - number of rolls, other quantities are given in Tab. 2.

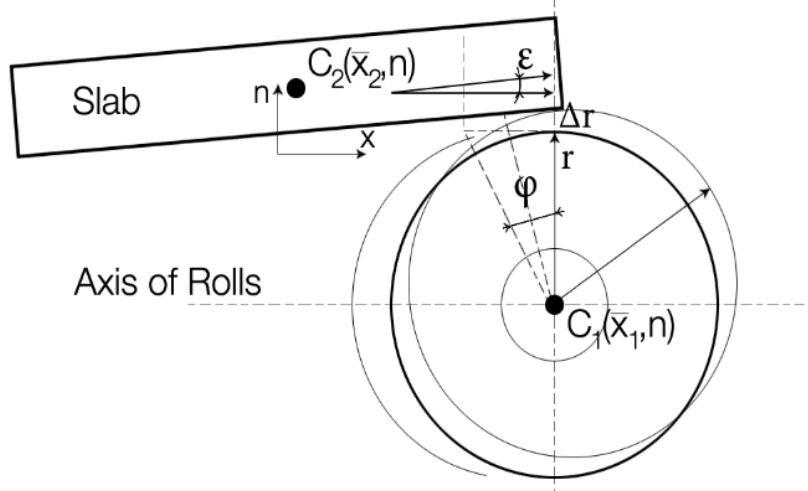

Fig. 3. Mechanism of eccentric movement of the roll (Dobrucki et al., 1991; Jagieła, 2003). Description: $C_{1}$ - centre of gravity of the roll, $C_{2}$ - centre of gravity of the slab, $\varepsilon$ - inclination angle of the slab with respect to the roll axis, $\varphi$ - angular displacement of the roll, $r$ - roll radius, $\Delta r$ - lift of the slab due to eccentricity of the roll

The second component of the load torque $T_{L}$ is connected with geometry and buckling of the conveying rolls. The geometry of the rolls in the considered section of the rolling table depends mainly on two factors: 1) variation of diameters of the individual rolls due of wear off and 2) eccentric movement of the rolls due to deflection of the frame and the bearings (Dobrucki et al., 1991), termic buckling (Dobrucki et al., 1991) and impacts from the metal strip when its end is turned up (Jagieła, 2003). The mechanism of the eccentric movement of the roll with respect to the conveyed metal strip is illustrated in Fig. 3.

The eccentric movement of the rolls produces impulse load forces $Q_{1}^{\varphi}$, that can be determined using formula (3) (Dobrucki et al., 1991; Jagieła, 2003):

$$
Q_{1}^{\varphi}=S^{\varphi} \cdot \sqrt{\frac{k_{1}}{m_{1}}} \cdot \frac{a}{\sqrt{a^{2}+\frac{1}{M}}}
$$

where the impulse impact $S^{\varphi}$ can be evaluated as:

$$
\begin{aligned}
& S^{\varphi}=\left(1+R^{*}\right) \cdot\left(v_{1}-v_{2}\right) \frac{m_{c} m_{1}}{m_{c}+m_{1}}=\left(1+R^{*}\right) . \\
& k_{v} \frac{m_{c} m_{1}}{m_{c}+m_{1}} \cdot v_{1}
\end{aligned}
$$

Explanation of quantities occuring in equations (3) and (4) and their values are collected in Tables 1 and 2 . The load torque of the rolling table due to the impulse eccentric impact is:

$$
T^{\varphi}=Q_{1}^{\varphi} \cdot \frac{D}{2}=S^{\varphi} \cdot \frac{D}{2} \cdot \sqrt{\frac{k_{1}}{m_{1}}} \cdot \frac{a}{\sqrt{a^{2}+\frac{1}{M}}}
$$

For the assumed asymmetry $k_{v}$ of the linear velocities the ratio of the eccentric impact torque $T^{\varphi}$ to the nominal electric torque

\begin{tabular}{|c|c|c|}
\hline Parameter & $\begin{array}{l}\text { Label and } \\
\text { value }\end{array}$ & Relation ships \\
\hline $\begin{array}{l}\text { Coefficient } \\
\text { of elasticity } \\
\text { of the drum }\end{array}$ & $\begin{array}{l}k_{1}=94 \mathrm{MN} / \mathrm{m} \\
q=0.5\end{array}$ & $\begin{array}{l}k_{1}=48 E J / q \mathrm{~L}^{3} \quad E=2.1 \cdot 10^{11} \mathrm{~N} / \mathrm{m}^{2} \\
J=\frac{\pi\left(D_{z}^{4}-D_{w}^{4}\right)}{64} \quad \mathrm{~m}^{4} \\
q=f_{1} / f_{0}-\text { ratio of deflections of the } \\
\text { drum and the bar (Dobrucki et al., } \\
\text { 1991) }\end{array}$ \\
\hline $\begin{array}{l}\text { Drum mass } \\
\text { reduction }\end{array}$ & $\begin{array}{l}m_{1}=2.64 \mathrm{~T} \\
\beta=0.8\end{array}$ & $\begin{array}{l}m_{1}=\beta \cdot m_{b} \\
\beta-\text { coefficient of the drums mass } \\
\text { reduction depending on proportion } \\
\text { of their dimensions (Dobrucki et al., } \\
\text { 1991) }\end{array}$ \\
\hline Parameters & $\begin{array}{l}A=9.06 \\
K=6.5 \\
M=0.1\end{array}$ & $a=\sqrt{\frac{K}{M}}+1 \quad K=\frac{k_{2}}{k_{1}} \quad M=\frac{m_{2}}{m_{1}}$ \\
\hline $\begin{array}{l}\text { Coefficient } \\
\text { of restitution }\end{array}$ & $R^{*}=0.15$ & $\begin{array}{l}\text { determined from the graf for steel } \\
\text { in function of the slab temperature } \\
\text { (Dobrucki et al., 1991). }\end{array}$ \\
\hline $\begin{array}{l}\text { Linear } \\
\text { velocities }\end{array}$ & $v_{1} . v_{2}$ & $\begin{array}{l}\text { velocities of the masses in the } n-x \\
\text { reference frame (Fig. 2); } \\
\text { linear velocity of the strip } v_{1} \text {; linear } \\
\text { velocity of the second motor roll } \\
\text { drum } v_{2}=\omega_{2} \cdot \frac{D_{z}}{2}\end{array}$ \\
\hline $\begin{array}{l}\text { Asymmetry } \\
\text { of velocities }\end{array}$ & $k_{v}=0.02$ & $k_{v}=\frac{v_{1}-v_{2}}{v_{1}}$ \\
\hline
\end{tabular}
of the roll:

$k^{\varphi}=\frac{T^{\varphi}}{T_{M}}=2,13$

Tab. 1. Parameters of impact forces acting on the roller drum while conveying the steel strip 
Tab. 2. Electric and mechanic parameters of the rolling table

\begin{tabular}{|c|c|}
\hline Parameter & Designation and value \\
\hline \multicolumn{2}{|l|}{ Roll parameters } \\
\hline a) external diameter & $D_{z}=0.4 \mathrm{~m}$ \\
\hline b) internal parameters & $D_{w}=0.3 \mathrm{~m}$ \\
\hline c) roll pin diameter & $D_{t}=0.2 \mathrm{~m}$ \\
\hline d) working length of the roll & $L=5.7 \mathrm{~m}$ \\
\hline e) distance between rolls & $l_{r}=0.8 \mathrm{~m}$ \\
\hline f) roll drum mass & $m_{h}=33 \mathrm{~T}$ \\
\hline g) moment of inertia of the roll & $\Theta_{r}=103 \mathrm{kgm}^{2}$ \\
\hline \multicolumn{2}{|c|}{ Strip parameters } \\
\hline a) linear velocity of the strip & $v_{1}=1.675 \mathrm{~ms}^{-1}$ \\
\hline b) strip mass & $m_{c}=10.7 \mathrm{~T}$ \\
\hline c) coefficient of strip-roll friction & $f_{r}=0.3$ \\
\hline d) coefficient of friction in the roll & $f_{t}=0.06 \div 0.08$ \\
\hline \multicolumn{2}{|c|}{ Electro-mechanical system parameters } \\
\hline $\begin{array}{l}\text { a) moment of inertia of the coupling and } \\
\text { the connectors }\end{array}$ & $\Theta_{s}=28 \mathrm{kgm}^{2}$ \\
\hline b) moment of inertia of the motor & $\Theta_{M}=30 \mathrm{kgm}^{2}$ \\
\hline c) motor torque & $T_{M}=1365 \mathrm{Nm}$ \\
\hline
\end{tabular}

The ratio of the static torque to the electric torque for the rolls and the strip whose parameters are given in Tab. 2 is:

$k^{M}=\frac{T_{S}}{T_{M}}=0.98$

Taking into account formula (1) and the components of the load torque defined by formulas (2) and (5), the equation of the roll dynamics for start-up and braking is as follows:

$$
\begin{aligned}
& \lambda T_{M}=\lambda\left[c_{M} \Phi I_{M}\right]=T_{L}(t)+T_{D}=T_{L}(t)+ \\
& \lambda\left[\left(\Theta_{\Sigma}+m_{c}^{*} g \frac{D_{z}^{2}}{4}\right) \frac{d \omega}{d t}\right]
\end{aligned}
$$

where: $c_{M}$ - torque constant od the dc motor, $\Phi$ - field flux of the dc motor, $I_{M}$ - armature current of the dc motor, $\lambda=+1$ for startup, $\lambda=-1$ for braking, $g=9.81 \mathrm{~m} / \mathrm{s}^{2}, \Theta_{\Sigma}=\Theta_{r}+\Theta_{s}+\Theta_{M}$.

The change of the static load $T_{L}$ due to variable force of the impulse load torque, whose resultant value is $\left(T_{L}+\Delta T_{L}\right)$, or due to change of the angular velocity $(\omega+\Delta \omega)$, causes response of the MULTIFEX control system resulting in change of the field flux $(\Phi+\Delta \Phi)$ that satisfies equation (8).

\section{SUPPLY AND CONTROL SYSTEMS OF DISCHARGE ROLLING TABLES WORKING IN THE MULTIFEX MODE}

The drive system of the discharge rolling table section of the conveyance line consists of six DC motors, which are directly engaged with the conveying rolls by short couplers (Fig. 1). The diagram of the power electronics supply system of the DC motors with high power control of the armature circuits and controlled field circuits is shown in Fig. 4. The choice of such a scheme of the supply and control was due to decision to remain the DC motors and necessity to maintain angular speeds of the individual motors that ensure equal linear speeds of all rolls, taking into account their geometric parameters.

The control of the thyristor systems that takes into account optimization of the THD coefficients and improvement of the power factor coefficient PFC (Friedli et al., 2014; Kolar and Friedli, 2013) is an important issue from the consumer power quality point of view. Therefore, the drive supply diagram shown in Fig. 4 includes the UPQ system for continuous monitoring and data acquisition.
The main parameters of the discharge rolling table drive with the separately excited DC motors are presented in Tab. 3.

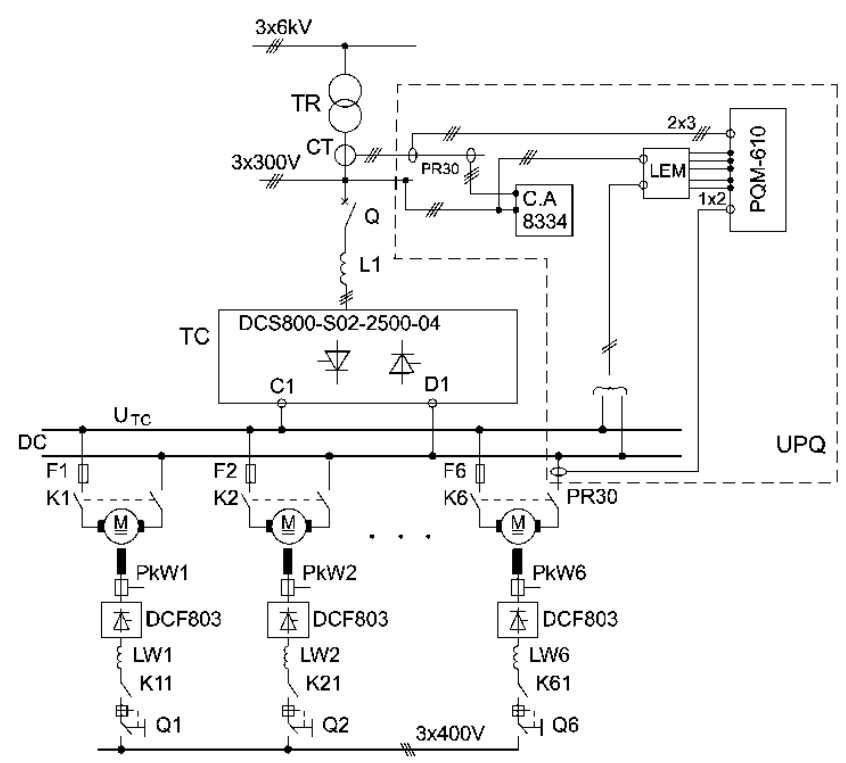

Fig. 4. Diagram of the drive supply system with outlined control system (UPQ) and pointed measurement points

Tab. 3. Main parameters of the discharge rolling table drive

\begin{tabular}{|c|}
\hline Motor and converter parameters \\
\hline \hline Motor type: $\mathrm{PXOm}-74 \mathrm{~b} / 01 ;$ quantity: 6 \\
\hline $\mathrm{P}=75 / 150 \mathrm{~kW} ; \mathrm{U}=220 / 440 \mathrm{~V} ; \mathrm{I}=370 \mathrm{~A} ;$ \\
$\mathrm{n}=525 / 1040 \mathrm{rpm} ; \mathrm{I}_{\mathrm{F}}=5 \mathrm{~A} ; \mathrm{T}=1365 \mathrm{Nm}$ \\
\hline Control range of angular and linear speed: \\
$\mathrm{n}_{\min }=80 \mathrm{rpm} \rightarrow \mathrm{n}_{\max }=140 \mathrm{rpm}$ \\
$\mathrm{V}_{\min }=3.35 \mathrm{~m} / \mathrm{s} \rightarrow \mathrm{V}_{\max }=5,86 \mathrm{~m} / \mathrm{s}$ \\
\hline Converter type: $\mathrm{DCS} 800-\mathrm{S} 02-2500-04$ \\
\hline $\mathrm{U}_{\text {supp }}=3 \times(230 \ldots 415) \mathrm{V} \mathrm{AC}$ \\
$\mathrm{IDC}_{\mathrm{DC}}=2500 \mathrm{~A} ; \mathrm{P}_{\mathrm{DC}}=1038 \mathrm{~kW}$ \\
\hline
\end{tabular}



Fig. 5. Communication of the field circuit supply units DCF803 with the main DCS800 converter

The principal aim of the control is to eliminate shearing of the conveyed slabs by minimizing differences of linear speed of the individual rolls. To achieve this aim a drive system including six DC motors with armature circuits connected to a single reverse thyristor converter and making up the MULTIFEX network was applied. The 
field circuits of the motors are supplied by separate 3T-3D thyristordiode bridges DCF803 and controlled from the main DCS800 converter via the DSL serial communication link connected to the SDCS-DSL board of the converter - Fig. 5 .

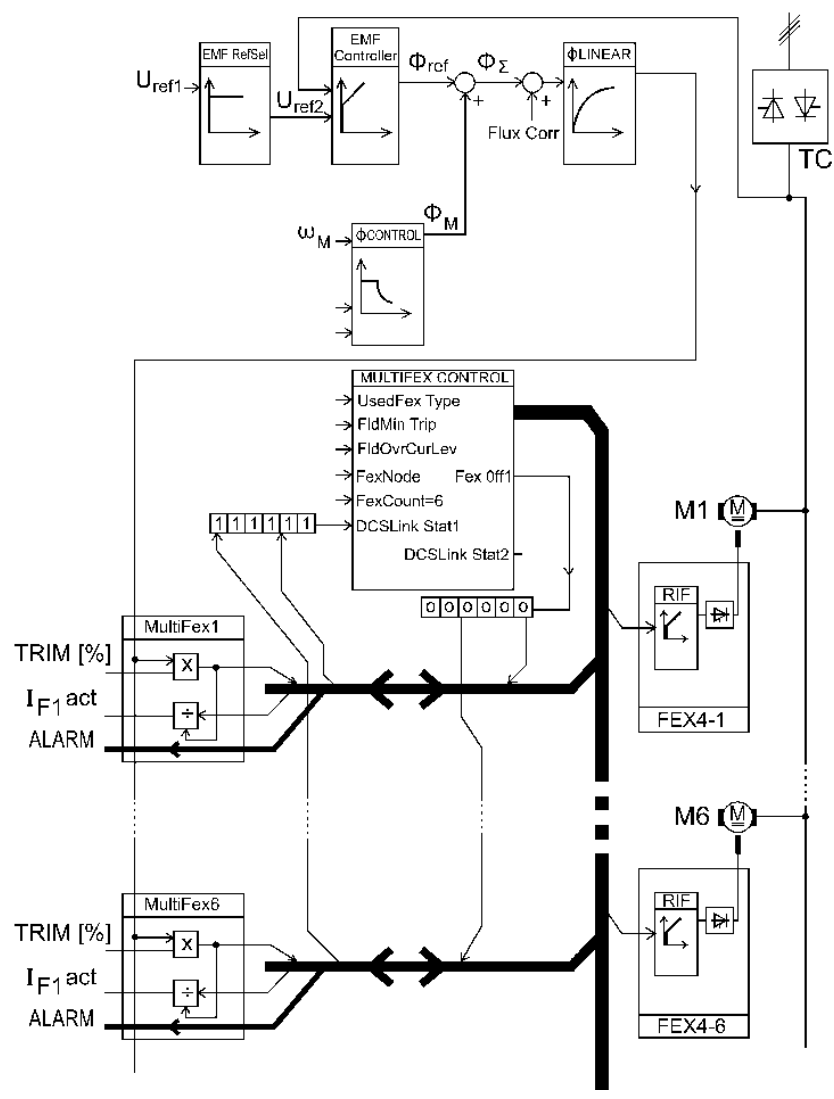

Fig. 6. Diagram of the MULTIFEX control

The control of the motor field circuits in the MULTIFEX system (Fig. 6) is based on $\mathrm{H} 8$ microcontrollers that control synchronization of the currents and handle errors. The microcontrollers communicate using the CAN serial interface. The control programs are stored in the FlashPROM memory and include:

- RIF PI control of the field current with the controller parameters,

- error handling and reset,

- synchronization and the PLL control,

- configuration of the current measurement channels.

The master loop in the MULTIFEX control diagram (Fig. 6) is the electromotive force (EMF) control loop. The output of the EMF controller is the reference input $\Phi_{\text {ref }}$ of the magnetic flux controller. The total flux $\Phi_{\Sigma}$ is the sum of $\Phi_{\text {ref }}$ and the second component $\Phi_{M}$, which is the output of the flux weakening controller $\Phi$ CONTROL. The input of the $\Phi$ CONTROL block is the angular speed signal from the tachometer or encoder or, as in the described case, it uses an adaptive algorithm for estimation of the angular speed in the multimotor drive.

The final reference signal of the field current is obtained after linearization $\Phi$ LINEAR. In each MultiFex motor control unit it is corrected by multiplier TRIM [\%] to achieve the required speed of each motor with minimum error. By applying the static correction TRIM, set separately for each field circuit, it is possible to minimize differences of linear speeds of the individual motors resulting from geometrical deviations of the roll sizes and deviations of the armature and field circuit resistances due to rewinding during the motors repair.

\section{DRIVE COMMISSIONING AND RESULTS OF MEASUREMENTS}

The presented multimotor drive system of the discharge rolling table is a part of the plate rolling line. Its task is to convey slabs and adapt the conveyance to the technological regime of the whole rolling line. The system has two modes of operation:

1. manual control by the operator;

2. automatic control cycle depending on operation of other discharge devices of the plate rolling line with control sequences planned online.

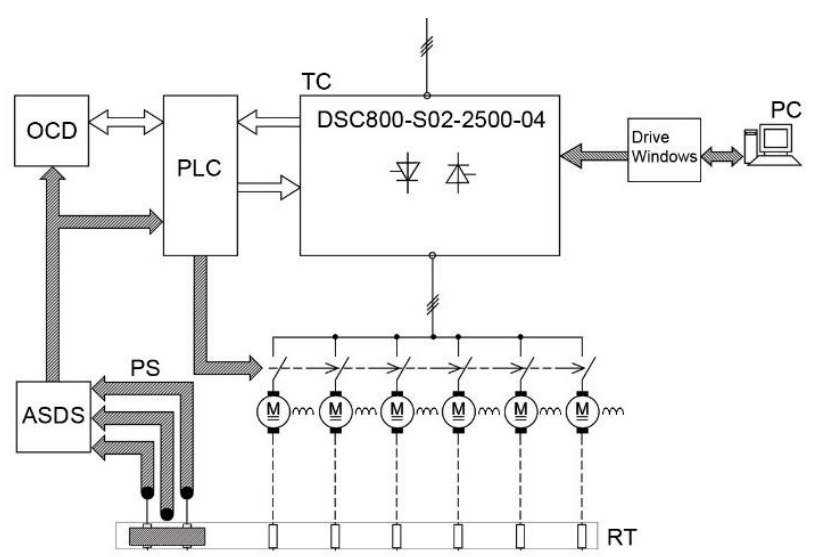

Fig. 7. Diagram of the DSC800 converter external control: OCD - operator control desk, RT - rolling table, PS - process signals, ASDS - automatic slab delivery system, TC - thyristor converter

The discharge rolling table drive is controlled hierarchically taking into account correlations with other devices of the rolling line. The first level of control is realized by the PLC controller (Fig. 7) that receives information from the automatic slab delivery bus. The delivery control works in sequential cycles: it conveys slabs from the pusher furnaces towards the break-down rolling stand. The PLC controller receives signals carrying information about the current run of individual stages of the technological process. The second, master level of control are commands from the operator control desk and the emergency stop signal that are basic safety protections of the staff and devices.

The reverse thyristor converter PT (DCS800) with the assigned field units FEX4-DCF803 should be precisely parameterized at the stage of the drive commissioning or restarting. A helpful tool for these purposes is the DriveWindow tool (Gała et al., 2009) (Fig. 5, Fig. 7). It is a multifunction application for: setting and adjusting control parameters, starting a drive, monitoring analog and digital quantities (signals) and controlling drives with $\mathrm{DC}$ or $\mathrm{AC}$ motors supplied respectively from DCS or ACS series converters and equipped with fiber-optic links.

In the considered system the application supervises simultaneous operation of the main DCS800 converter and six field circuit converters DCF803. It collects current values of signals and can present them, e.g. in the same graph for comparison. 


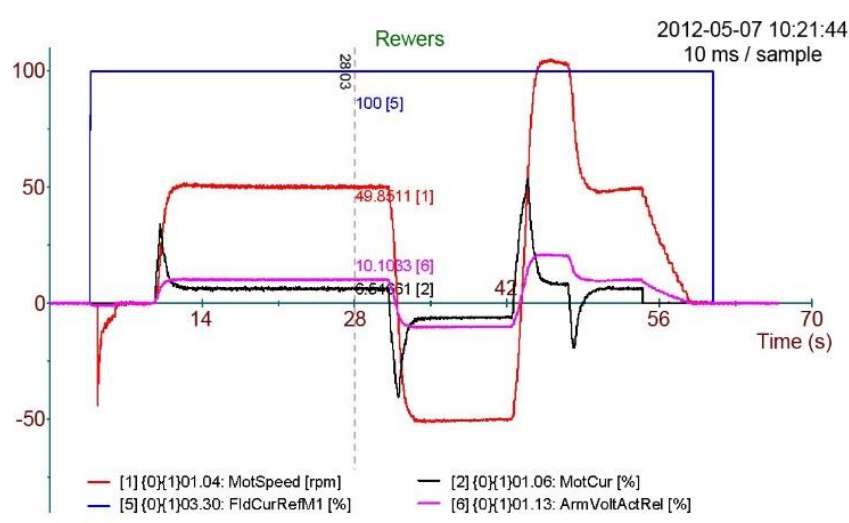

Fig. 8. Waveforms of electromechanical quantities of the discharge rolling table drive

All the monitored data and parameters can be saved in the files for further offline analysis or edition. The files with the drive settings, stored in the archive or edited offline, can be loaded to the converter memory which minimizes the time of starting the drive or restarting it after a failure. An example of the DriveWindow capabilities is presented in Fig. 8. The graph shows waveforms of the voltage and total current of the armature circuits as well as the estimated angular speed and field current of a single motor (they are the same for the other motors) recorded during the startup, reverse, rapid change of the angular velocity (commanded by the external controller) and finally the stop of the drive.



Fig. 9. Waveforms of the DCS800 converter supply voltage and current

Another tool for aiding the process of setting the drive operation parameters is the computer measurement unit PQM-610. It includes voltage and current transducers LEM, current measurement pincers PR-30 (Fig. 4) and the DASYLab software. The metrological parameters of the measurement unit ensure accuracy up to $0.1 \%$ as far as the higher-order harmonic content coefficients THD of the voltage and current are concerned. The complement of the PQM-610 unit is the power quality analyzer CA8334 connected to the low voltage network $3 \times 300 \mathrm{~V}$ and to the secondary circuit of the current measuring transformer CT 4000A/5A (Fig. 4). Those two measurement devices make it possible to analyze the influence of the rolling table drive on the local internal medium and low voltage network, in particular arising of higher-order harmonics of the current. Example waveforms of the converter phase-to-phase supply voltage and the phase current are shown in Fig. 9.



Fig. 10. Waveforms of the DCS800 converter output voltage and current at the idle run

The commissioning of the discharge rolling table drive gave opportunity to conduct series of measurements. One of them shows work of individual thyristors of the $2 \times 6$ T bridge. The graph in Fig. 10 presents waveforms of the voltage (red line) and current (blue line) drawn by the six armature circuits of the separately excited motors. The graph in Fig. 10 shows deep decrease of the motors angular velocity down to $31 \mathrm{rpm}$, which is equivalent to voltage of 13 $\mathrm{V}$ on the converter DC bus. The load voltage and current measurement was carried out at the idle run of the motors with no slabs conveyed.

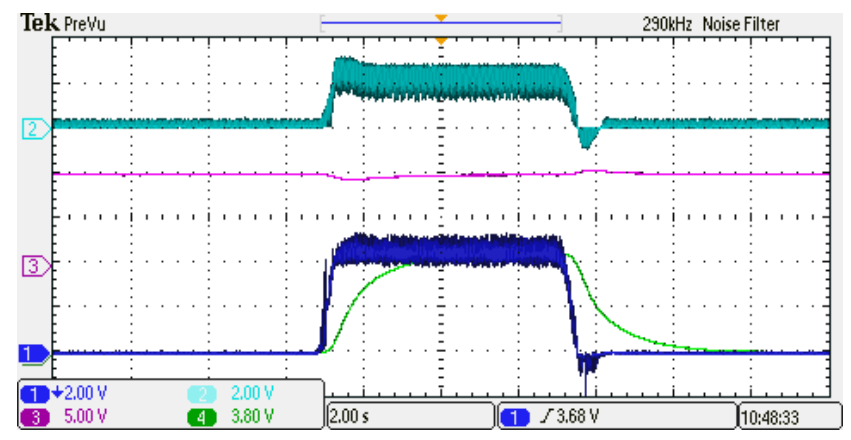

Fig. 11. Current waveform $\left(I_{M}\right)$, angular speed $(n)$, load torque $\left(I_{M}\right)$ and estimated torque $\left(T_{E S}\right)$ in the case of the first load



Fig. 12. Current waveform $\left(I_{M}\right)$, angular speed $(n)$, load torque $\left(I_{M}\right)$ and estimated torque $\left(T_{E S}\right)$ in the case of the second load

The measurements of the actual load torque and its corresponding estimated value of electromagnetic torque generated by the converter were conducted during the transport of hot slabs 
to the break-down rolling stand. The results of experiment involved two tests:

1) pulse roller load during the slab transport (Fig. 11);

2) load of a roller in a rolling table at the time of the slab transport direction change (Fig. 12).

In both cases clear differences between the actual torque $T_{L}$ and the estimated torque $T_{E S}$ are visible. Such differences occur especially in transient states (load torque impact, slowdown and change of the motor rotation direction). In steady states both values are very close and the absolute error does not exceed 2 percent

$\delta=\frac{\left|T_{L}-T_{E S}\right|}{T_{L}} 100 \% \leq 2 \%$

\section{SUMMARY}

The drive system described in the paper was implemented in the modernized rolling line. It meets all technical requirements of a modern plate rolling process.



Fig. 13. Interior of the field circuits power supply cubicle with the FEX4 boards

The photo in Fig. 13 shows interior of the cubicle with six FEX4 boards for powering the field circuits of the rolling table drive motors. On the basis of the drive implementation tests it can be stated that it is possible to supply a group of separately excited DC motors from a single reverse thyristor converter connected with several separate controllers of the motors field currents. In the presented case those controllers communicate with the main converter via the DSL link. Such a scheme allows for correction of the field currents of individual motors which results in very good synchronization of the motors and rolls speeds.
The presented discharge rolling table drive has good dynamic properties. The change of the slab conveying direction for the angular speed setting of almost $50 \%$ of the full range takes 1 second (see Fig. 8) and the dynamic current peak during that reverse exceeds 5 times the steady state current.

The DriveWindow software (Gała et al., 2003) is a modern and effective tool that aids practical application of the drive and facilitates carrying out various tests necessary during commissioning of the DCS and ACS drive systems.

\section{REFERENCES}

1. Abu-Rub H., Guziński J., Jąderko A., Krzemiński Z. (2004), Practical Realisation of New Method of Synchronisation for Controlled Rectifier, International Conference on Power Electronics, Intelligent Motions and Power Quality PCIM 2004, Nuremberg, Germany, $533-538$.

2. Abu-Rub H., Guziński J., Jaderko A., Krzemiński Z. (2005), Digital Implementation of a Novel Controlled Rectifier Synchronization Method, Electric Power Components and Systems, Vol. 33 (10), $1123-1135$.

3. Dobrucki W., Gregorczyk R., Świątoniowski A., Zawada S. (1991), Introduction to design and operation of rolling mills - Calculations and experiments, Wydawnictwo AGH, Kraków, (in Polish).

4. Friedli T., Hartmann M., Kolar J.W. (2014), The Essence of ThreePhase PFC Rectifier Systems-Part II, IEEE Transactions on Power Electronics, Volume: 29 (2), 543-560.

5. Gała M., Rak J., Kępiński M., Jagieła K. (2009), Application of Drive Window software for $A C$ and $D C$ drives operation states diagnostics, Electric Machines - Problem Issues, No.82/2009, BOBRME KOMEL Katowice, 33-38, ISSN 0239-3646, (in Polish).

6. Guziński J., Diaguet M., Krzemiński Z., Lewicki A., Abu-Rub H. (2009), Application of speed and load torque observers in high-speed train drive for diagnostic purposes, IEEE Transactions on Industrial Electronics, Vol 57(2), 565-574

7. Jagieła K. (1997), Theoretical issues in calculation of load parameters of rolling table motors. Research Notes of Lvov State University of Technology - Electrical power engineering and electro-mechanical systems Systemy, № 340, 142-147, (in Ukrainian).

8. Jagieła K. (2003), Model of metallurgical discharge rolling table, Electrical Review, No.6/2003, 448- 452.

9. Jagieła K., Gała M. (2008), Setting screw electrical drive of the vertical milling cage using MASTER- FOLLOWER control, IX Inter-national Scientific Conference "New Technologies in Metallurgy and Materials Engineering", Metallurgy Committee PAS, Czestochowa University of Technology, Vol. 1, 146-149 (in Polish).

10. Kolar J. W., Friedli T. (2013), The Essence of Three-Phase PFC Rectifier Systems-Part I, IEEE Transactions on Power Electronics, Volume: 28 (1), 176-198.

11. Michael C.A., Safacas A.N. (2007), Dynamic and Vibration Analysis of a Multimotor DC Drive System With Elastic Shafts Driving a Tissue Paper Machine, IEEE Transactions on Industrial Electronics, Vol. 54 (4), 2033-2046.

12. Multifex motor control for roller tables DCS800 Drives (20 to $5200 \mathrm{~A}$ ), ABB Automation Products, Germany, 05-2008. 